Zanarini, M. C., Frankenburg, F. R., Hennen, J., et al (2005) The McLean Study of Adult Development (MSAD): overview and implications of the first six year of prospective follow-up. Journal of Personality Disorders, 19, 505-523.

P. Fonagy University College London and The Anna Freud Centre, Gower Street, London WCIE 6BT, UK. E-mail: e.allison@ucl.ac.uk

A. Bateman Halliwick Unit, St Ann's Hospital, London, UK

\section{Psychological morbidity during pregnancy and low birth weight}

Patel \& Prince (2006) reported cohort data from Goa, India that showed maternal psychological morbidity to be independently associated with low birth weight $(<2.5 \mathrm{~kg})$ and to have an adverse impact on foetal growth. We agree with the authors' findings and consider that low birth weight as a consequence of treatable psychological morbidity during pregnancy should be an important health priority worldwide.

Recently we investigated whether exposure to the bombing of Belgrade in 1999 during pregnancy was associated with lower birth weight of babies. Mean birth weight of infants born in 1999 in Belgrade was compared with that of those born in 1996 and 2003 (no stressful events affected the city in these years). We collated data on the number of deliveries in Belgrade, birth weight, the percentage of stillborn babies, the percentage of premature births and maternal age from information on deliveries collected annually by the Institute of Public Health, Belgrade. Secondary analysis of this data-set, despite some methodological limitations, revealed that mother's age, percentage of stillborn babies and the percentage of premature births did not differ between the years but there was a significant decrease in mean birth weight of all babies born in 1999 compared with the other 2 years $(3.111 \mathrm{~kg} v .3 .278 \mathrm{~kg}$ in 1996 and $3.223 \mathrm{~kg}$ in 2003) $(P<0.05)$. Similarly, Lederman et al (2004) showed that infants born at term to women who were pregnant on 11 September 2001, and who were living within a 2-mile radius of the World Trade Center (New York) during the month after the bombings, showed significant decreases in birth weight and height.

Infants of low birth weight who are born at term are more likely to experience psychological distress in adulthood (Wiles et al, 2005) and to have an increased risk of affective illness (Gale \& Martyn,
2004). Therefore not only is research on maternal psychological morbidity very important but a specific screening strategy and preventive plans for infants at risk of low birth weight are urgently needed worldwide.

Gale, C. R. \& Martyn, C. N. (2004) Birth weight and later risk of depression in a national birth cohort. British Journal of Psychiatry, 184, 28-33.

Lederman, S. A., Rauh, V., Weiss, L., et al (2004) The effects of world trade center event on birth outcomes among term deliveries at three lower Manhattan hospitals. Environmental Health Perspectives, II2, 1172-1178.

Patel, V. \& Prince, M. (2006) Maternal psychological morbidity and low birth weight in India. British journal of Psychiatry, 188, 284-285.

Wiles, N. J., Peters, T. J., Leon, D. A., et al (2005) Birth weight and psychological distress at age 45-6I years: results from the Aberdeen Children of the 1950s cohort study. British Journal of Psychiatry, 187, 21-28.

N. Maric Institute of Psychiatry, UCC, Pasterova 2, Belgrade II000, and Medical School, University of Belgrade, Serbia and Montenegro.

E-mail: nadjamaric@yahoo.com

M. Jasovic-Gasic Institute of Psychiatry, UCC Belgrade, and Medical School, University of Belgrade, Serbia and Montenegro

D. Britvic Institute of Psychiatry, UCC, Belgrade, Serbia and Montenegro

\section{'Delay' hypothesis of onset of antidepressant action}

The 'delay' hypothesis has had a long life and has greatly influenced the treatment of depression and research aimed at the development of new 'more rapidly acting' drugs. Evidence has gradually accumulated that the hypothesis is inaccurate and its entrance into the lore of clinical practice and textbooks is unwarranted. The hypothesis was derived from studies that did not test it directly and are now viewed as both conceptually and methodologically inadequate. In his editorial, Mitchell (2006) makes salient points and, after reviewing some of the current literature, comes to the correct conclusions. However, our earlier results that refuted the hypothesis (Katz et al, 1987, 1991) and a more recently published study (Katz et al, 2004), designed to definitively test the 'delay' notion, were not referenced. Their omission leaves important gaps.

Mitchell highlights the inadequacy of the 'outcome' measures used in early studies and the importance of distinguishing 'improvement' from 'full response'. The central criticism of the early work (e.g. by Gelenberg \& Chesen, 2000) is that most information was derived from clinical trials, not studies designed to accurately estimate onset and time course of changes. Such studies require a placebo control, sensitive measures of behavioural change (beyond the Hamilton Rating Scale for Depression) and frequent early assessment. The meta-analyses of Stassen et al (1997) came close to achieving these aims. However, no study had met all the necessary requirements until that conducted by our group (Katz et al, 2004). This measured the major behavioural components of the disorder intensively at 3-day intervals, operationally distinguished improvement and full response and compared pharmacologically different antidepressants (a selective serotonin reuptake inhibitor and a selective noradrenaline reuptake inhibitor) with placebo. In targeting the issue directly, it used appropriate statistical methods to investigate whether algorithms could be developed to predict treatment response from early behavioural changes, problems alluded to by Mitchell. We understand that an editorial cannot provide an exhaustive review but believe the information above will contribute to the important issues addressed.

Gelenberg, A. J. \& Chesen, C. L. (2000) How fast are antidepressants? Journal of Clinical Psychiatry, 61, $7|2-72|$

Katz, M. M., Koslow, S. H., Maas, J. W., et al (1987) The timing, specificity and clinical prediction of tricyclic drug effects in depression. Psychological Medicine, I7, 297-309.

Katz, M. M., Koslow, S. H., Maas, J.W., et al (1991) Identifying the specific clinical actions of amitryptyline: Interrelationships of behavior, affect, and plasma levels in depression. Psychological Medicine, 2I, 599-6II.

Katz, M. M., Tekell, J. L., Bowden, C. L., et al (2004) Onset and early behavioral effects of pharmacologically different antidepressants and placebo in depression. Neuropsychopharmacology, 29, 566-579.

Mitchell, A. J. (2006) Two-week delay in onset of action of antidepressants: new evidence. British Journa of Psychiatry, 188, 105-106.

Stassen, H. H., Angst, J. \& Delini-Stula, A. (1997) Delayed onset of action of antidepressants? Survey of recent results. European Psychiatry, 12, 166-176.

M. M. Katz Department of Psychiatry, University of Texas Health Science Center, 7703 Floyd Curl Drive, San Antonio, Texas 78229-3900, USA E-mail: katzmm@verizon.net

A. Frazer Department of Pharmacology, University of Texas Health Science Center at San Antonio, Texas, USA

C. L. Bowden Department of Psychiatry, University of Texas Health Science Center at San Antonio, Texas, USA 